ARTICLE

DOI: $10.1038 / s 41467-018-07427-z$

\title{
Interconvertible vanadium-seamed hexameric pyrogallol[4]arene nanocapsules
}

\author{
Kongzhao Su${ }^{1}$, Mingyan Wu${ }^{1}$, Daqiang Yuan (D ${ }^{1} \&$ Maochun Hong ${ }^{1}$
}

Research into stimuli-responsive controlled self-assembly and reversible transformation of molecular architectures has received much attention recently, because it is important to understand and reproduce this natural self-assembly behavior. Here, we report two coordination nanocapsules with variable cavities: a contracted octahedral $V_{24}$ capsule and an expanded ball-shaped $V_{24}$ capsule, both of which are constructed from the same number of subcomponents. The assemblies of these two $V_{24}$ capsules are solvent-controlled, and capable of reversible conversion between contracted and expanded forms via control of the geometries of the metal centers by association and dissociation with axial water molecules. Following such structural interconversions, the magnetic properties are significantly changed. This work not only provides a strategy for the design and preparation of coordination nanocapsules with adaptable cavities, but also a unique example with which to understand the transformation process and their structure-property relationships.

\footnotetext{
${ }^{1}$ State Key Laboratory of Structure Chemistry, Fujian Institute of Research on the Structure of Matter, Chinese Academy of Sciences, Fuzhou, 350002 Fujian, China. Correspondence and requests for materials should be addressed to D.Y. (email: ydq@fjirsm.ac.cn)
} 
T he design and synthesis of discrete metal-organic nanocapsules (MONCs) with specific geometries and cavities have been investigated extensively due to not only their interesting structures ${ }^{1-3}$, but also their promising applications in supramolecular chemistry ${ }^{4-6}$ and material science ${ }^{7-9}$. To date, a large number of MONCs have been synthesized from metal ions or metal clusters with different coordination environments and organic linkers with various shapes ${ }^{10-12}$. Of particular recent interest is control of the self-assembly of the MONCs by external stimuli ${ }^{13,14}$ including light ${ }^{15,16}$, electricity ${ }^{17}, \mathrm{pH}^{18}$, guests ${ }^{19}$, and solvents ${ }^{20}$. Studies of this self-assembly may help us to understand and further mimic stimuli-responsive structural reorganization processes in biological systems. However, the structural transformations of the reported stimuli-responsive MONCs are usually accompanied by major changes in the species and number of subcomponents including metal centers and ligands. In contrast, exploration of stimuli-responsive MONCs with equal subcomponents ${ }^{21,22}$, or MONC quasi-isomers ${ }^{23,24}$ with the same metal centers, but some different coordinated components ${ }^{15,16}$, which act similarly to natural macromolecules is still in its infancy. Recognition of the reversible structural interconversion between such isomers or quasi-isomers will not only provide new approaches to broaden the preparation of MONCs with different shapes, but also an understanding of their structure-property relationships, such as host-guest recognition, drug delivery and release, and supramolecular catalysis ${ }^{16,25,26}$.

C-alkylpyrogallol[4]arenes (abbreviated as $\operatorname{PgC}_{n}$, where $n$ is the length of the associated alkyl tail), which are vase-shaped macrocyclic host molecules composed of 1,2,3-trihydroxybenzene units, have been determined over the past decade to be versatile building blocks for the construction of supramolecular complexes ${ }^{27}$. For example, $\mathrm{PgC}_{n}$ can assemble itself to form isolated MONCs $^{28,29}$, hydrogen-bonded capsules ${ }^{30,31}$, hydrogen-bonded/ metal-organic nanotubes ${ }^{32,33}$, and supramolecular organic frameworks ${ }^{34}$.

Since the initial discovery by Atwood et al. in $2005^{35}$ of $\mathrm{PgC}_{n^{-}}$ based MONCs constructed from six $\mathrm{PgC}_{n}$ units and $24 \mathrm{Cu}^{2+}$ ions, a number of studies have demonstrated that $\mathrm{PgC}_{n}$ can selfassemble into octahedral hexameric $\mathrm{M}_{24}(\mathrm{M}=\mathrm{Mg}, \mathrm{Co}, \mathrm{Ni}, \mathrm{Cu}$, and $\mathrm{Zn})^{36-40}$, spherical dimeric $\mathrm{M}_{8}(\mathrm{M}=\mathrm{Co}, \mathrm{Ni}, \mathrm{Cu}$, and $\mathrm{Zn})^{41-43}$, "rugby ball" shaped hexameric $\mathrm{Ga}_{12}{ }^{44}$ or mixed nanocapsules ${ }^{45-47}$. Interestingly, spherical $\mathrm{Cu}_{8}$ and $\mathrm{Zn}_{8}$ dimers can be linked by $4,4^{\prime}$-bipyridine ligands into a one-dimensional coordination polymer ${ }^{48}$ and an MOF-like structure ${ }^{49}$, respectively. However, $\mathrm{PgC}_{n}$-based MONCs are limited to the aforementioned metal ions, and still have the possibility of synthesizing new $\mathrm{PgC}_{n}$-based MONCs and exerting control over their self-assembly behavior.

Vanadium is of particular interest in this context owing to its various coordination behaviors, valence states, and promising applications in areas such as magnetism ${ }^{50-52}$, optics ${ }^{53}$, and catalysis ${ }^{54}$. Currently, the number of known vanadium capsules is limited ${ }^{55-58}$ and here we report an interesting example of solventresponsive assembly of coordination nanocapsule quasi-isomers with distinct geometries. This includes a contracted octahedral capsule $\left(\mathrm{V}_{24}\right.$-oct) with the inner cavity of $1000 \AA^{3}$, and an expanded ball-shaped capsule $\left(\mathrm{V}_{24}\right.$-ball $)$ with inner cavity of 1400 $\AA^{3}$, from the same number of subcomponents including 24 vanadium centers and 6 pyrogallol[4]arene units (Fig. 1). These two $V_{24}$ capsules represent an example of a metal displaying versatility and forming different $\mathrm{PgC}_{n}$-based hexamer capsules.

\section{Results}

Synthesis and characterization of $\mathrm{V}_{24}$ octahedron and ball. CPropylpyrogallol[4]arene $\left(\mathrm{PgC}_{3}\right.$, Fig. 1) was synthesized as reported by Gerkensmeier et al. ${ }^{59}$ by a condensation reaction of pyrogallol and butanal catalyzed by concentrated hydrochloric acid. The reaction of $\mathrm{PgC}_{3}$ with $\mathrm{VOSO}_{4} \cdot 5 \mathrm{H}_{2} \mathrm{O}$ in $\mathrm{CH}_{3} \mathrm{CN} / \mathrm{H}_{2} \mathrm{O}$ solution $(10: 1, \mathrm{v} / \mathrm{v})$ at $80^{\circ} \mathrm{C}$ for three days yields green rhombic crystals of $\mathrm{V}_{24}$-oct- $\alpha$ with the formula $\left[\mathrm{V}_{24} \mathrm{O}_{24}\left(\mathrm{H}_{2} \mathrm{O}\right)_{24}\right.$ $\left.\left(\mathrm{C}_{40} \mathrm{H}_{40} \mathrm{O}_{12}\right)_{6}\right] \cdot$ (solvent $)_{x}$. Single-crystal X-ray diffraction analysis shows that the $\mathrm{V}_{24}$-oct- $\alpha$ crystallizes in the trigonal system with space group $R-3$ and consists of $6 \mathrm{PgC}_{3}$ units and $24 \mathrm{~V}$ ions arranged in 8 trinuclear $V_{3}$ clusters capping the face of the octahedron (Fig. 2a). The overall geometry of this capsule is similar to the previously reported octahedral hexameric $\mathrm{M}_{24}$ $(\mathrm{M}=\mathrm{Mg}, \mathrm{Cu}, \mathrm{Co}, \mathrm{Ni}$, and $\mathrm{Zn})$ capsules $^{36-40}$. Inspection of the crystal structure of $\mathrm{V}_{24}$-oct- $\alpha$ reveals that each $\mathrm{V}_{3}$ cluster is held together by three pyrogallol $(\mathrm{Pg})$ units from different bowl-shape $\mathrm{PgC}_{3}$ ligands (Fig. 2b). The angle between the two opposite upper-rim oxygen atoms and the lower-rim centroid at the base of the $\mathrm{PgC}_{3}$ ligand is about $108.9^{\circ}$ and the separation between two opposite faces of the octahedron, measured from the opposite centroids of the $V_{3}$ clusters is approximately $14.3 \AA$ (Supplementary Figures 4 and 5). These three $V$ centers adopt octahedral geometries, and each one is coordinated with four phenoxyl

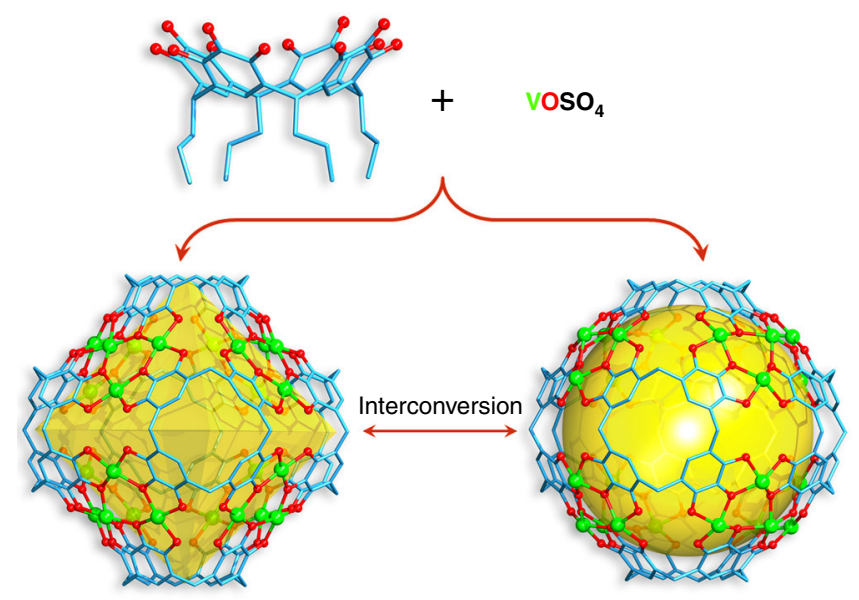

Fig. 1 Controlled self-assembly and interconversions of $V_{24}$ capsules. Chemical structure of hexameric pyrogallol[4]arene $V_{24}$ octahedron and $\mathrm{V}_{24}$ ball from $6 \mathrm{PgC}_{3}$ ligands and 24 vanadium ions. Vanadium is green, oxygen red and carbon blue

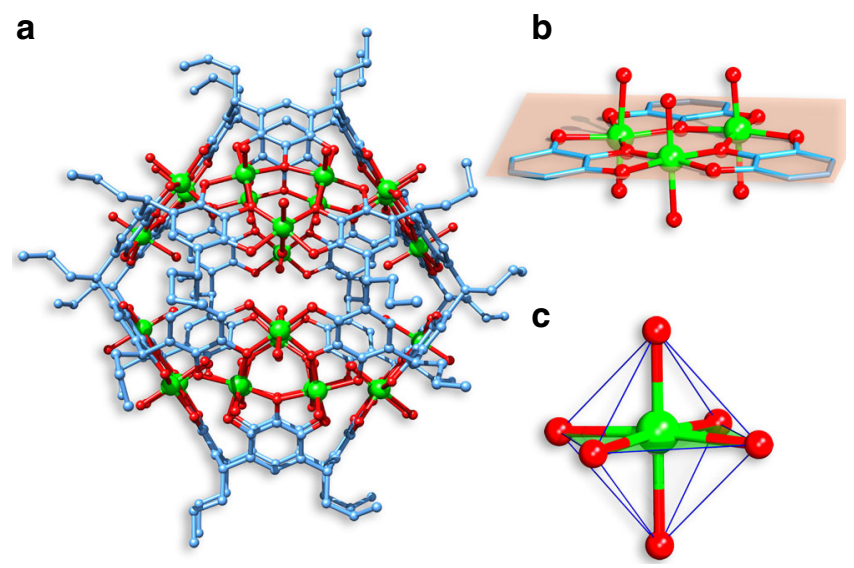

Fig. 2 Structural representations of $V_{24}$-oct- $\alpha$ from $X$-ray diffraction data. a Molecular structure of $V_{24}$-oct- $\alpha$. b Metal-ligand arrangement and c coordination geometries of $\mathrm{V}$ ions within the capsule 


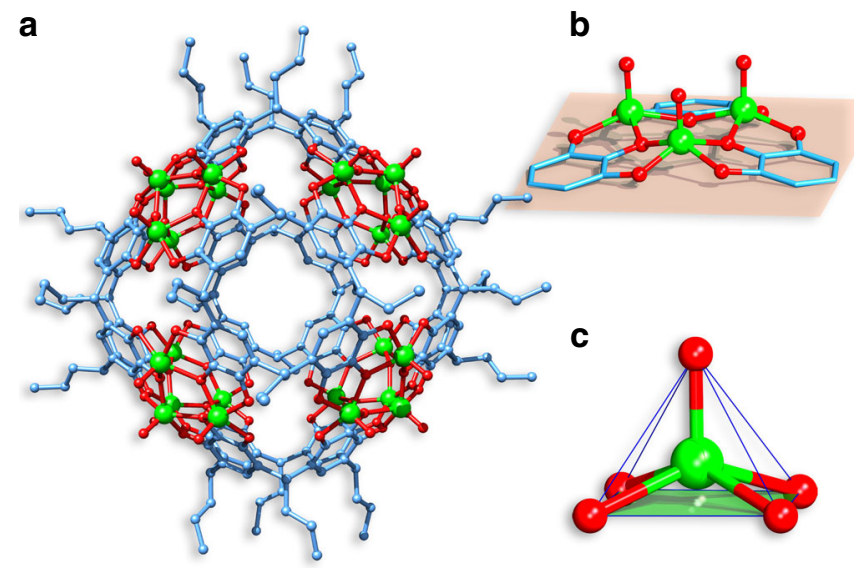

Fig. 3 Structural representations of $V_{24}$-ball- $\beta$ from $X$-ray diffraction data. a Molecular structure of $V_{24}$-ball- $\beta$. b Metal-ligand arrangement and c coordination geometries of $\mathrm{V}$ ions within the capsule

oxygen atoms from two different $\mathrm{PgC}_{3}$ ligands, one interior water molecule, and one exterior oxygen atom (Fig. 2c). Further analysis shows that three $\mathrm{V}$ centers, situated at the vertices of an approximately equilateral triangle, in which $\mathrm{V}$... V distances are in the range of 3.752-3.763 $\AA$, are linked by three phenoxyl oxygen atoms to form a planar $\mathrm{V}_{3} \mathrm{O}_{3}$ array. In this array, the $\mathrm{V} \cdots \mathrm{O}$ distances range from 1.987-2.001 $\AA$, the $\mathrm{O}-\mathrm{V}-\mathrm{O}$ angles range from $98.18-99.09^{\circ}$, and the $\mathrm{V}-\mathrm{O}-\mathrm{V}$ angles range from $140.08-141.17^{\circ}$. The capsule contains an internal cavity with a volume of $\sim 1000 \AA^{3}$, calculated using VOIDOO with a probe radius of $1.2 \AA$. Bond valence sum (BVS) calculations and EPR analysis reveal that the vanadium centers in $\mathrm{V}_{24}$-oct- $\alpha$ are at +4 oxidation states (Supplementary Table 2 and Supplementary Figure 1). In addition, the IR spectrum of $V_{24}$-oct- $\alpha$ shows the characteristic $\mathrm{V}=\mathrm{O}$ band in the frequency range $950-990 \mathrm{~cm}^{-1}$ (Supplementary Figure 2). It is interesting that the introduction of $N, N$-dimethylformamide (DMF) to the reaction of $\mathrm{V}_{24}$-oct- $\alpha$ produces its polymorph $\mathrm{V}_{24}$-oct- $\beta$ which crystallizes in the triclinic space group $P-1$.

Interestingly, changing the $\mathrm{CH}_{3} \mathrm{CN} / \mathrm{H}_{2} \mathrm{O}$ solvent in the preparation of $\mathrm{V}_{24}$-oct- $\alpha$ to $\mathrm{NMF} / \mathrm{CH}_{3} \mathrm{OH}(1: 1, \mathrm{v} / \mathrm{v}$; $\mathrm{NMF}=\mathrm{N}$ methylformamide) affords green tetragonal prism crystals of $\mathrm{V}_{24^{-}}$ ball- $\beta$ : $\left[\mathrm{V}_{24} \mathrm{O}_{24}\left(\mathrm{C}_{40} \mathrm{H}_{40} \mathrm{O}_{12}\right)_{6}\right] \cdot$ (solvent $)_{x}$, which crystallizes in the tetragonal space group $P 4 / m n c$ and contains the same number of components as $\mathrm{V}_{24}$-oct- $\alpha$ (Fig. 3a). This capsule can be regarded as an expanded structure of the $\mathrm{V}_{24}$-oct- $\alpha$ for two main reasons. The angle between the two opposite upper-rim oxygen atoms and the lower-rim centroid at the base of the $\mathrm{PgC}_{3}$ ligand has expanded to $123.1^{\circ}$ and the separation between two opposite centroids of $\mathrm{V}_{3}$ clusters in this ball increases to $16.7 \AA$, compared to $V_{24}$-oct- $\alpha$ (Supplementary Figures 4 and 5 ). As a result of these expansions, the inner cavity volume of the $V_{24}$-ball- $\beta$ increases to $\sim 1400 \AA^{3}$, which is $\sim 400 \AA^{3}$ larger than the cavity in $V_{24}$-oct- $\alpha$. Upon close examination, their structural transformations can be seen to be due to the coordination geometry differences in $\mathrm{V}$ centers. In this case, all the $\mathrm{V}$ ions are five-coordinated in squarepyramidal coordination geometries and coordinated by four phenoxyl oxygen atoms from two different $\mathrm{PgC}_{3}$ ligands and one exterior oxygen atom (Fig. 3c). The changes of coordination geometry in the $\mathrm{V}$ ions have a large influence on the bond angles and the shape of the $\mathrm{V}_{3} \mathrm{O}_{3}$ array from the aforementioned $\mathrm{V}_{24^{-}}$ oct- $\alpha$. Specifically, the $\mathrm{V}_{3} \mathrm{O}_{3}$ array in $\mathrm{V}_{24}$-ball- $\beta$ is concavoconvex with $\mathrm{V} \cdots \mathrm{O}$ distances ranging from $1.953-2.037 \AA, \mathrm{O}-\mathrm{V}-\mathrm{O}$ angles ranging from $88.52-89.43^{\circ}$ and $\mathrm{V}-\mathrm{O}-\mathrm{V}$ angles ranging from $134.38-137.12^{\circ}$ (Fig. 3b). Except for the V...O distances, it is

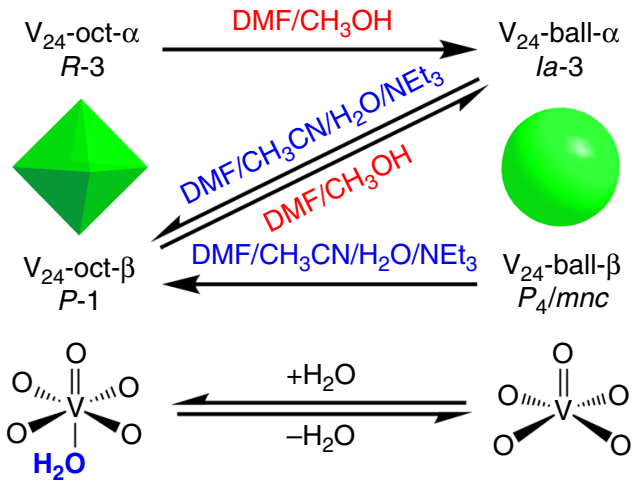

Fig. 4 The transformation mechanism of $V_{24}$ capsules. The transformation mechanism of $V_{24}$ octahedron and ball can be achieved by controlling the geometries of vanadium ions by association and dissociation with axial water molecules in different solvent conditions

clear that the $\mathrm{O}-\mathrm{V}-\mathrm{O}$ and $\mathrm{V}-\mathrm{O}-\mathrm{V}$ angles in this capsule are much smaller than those in $\mathrm{V}_{24}$-oct- $\alpha$ quasi-isomer. BVS calculations and EPR analysis together with IR spectra reveal that the vanadium centers in $\mathrm{V}_{24}$-ball- $\beta$ are at +4 oxidation states with a $\mathrm{VO}^{2+}$ form (Supplementary Table 3 and Supplementary Figures 1 and 3), which are the same to those in $V_{24}$-oct- $\alpha$. Whereas the structural differences in previously reported MONC isomers and quasi-isomers arise from the plasticity of the ligands ${ }^{15,16,21,22}$, these two different types of $\mathrm{V}_{24}$ capsules represent an example of MONC quasi-isomers whose structural differences stem from the coordination diversity of metal centers. By replacing the NMF with DMF in the same reaction, its polymorph $\mathrm{V}_{24}$-ball- $\alpha$ was obtained and was found to crystallize in a cubic system with the space group Ia-3.

Interconversions between $\mathbf{V}_{\mathbf{2 4}}$ capsules. It has been observed that the five-coordinate square pyramidal and six-coordinated octahedral oxidovanadium complexes can interconvert by associating and disassociating an axial molecule ${ }^{60-62}$. With this in mind, we searched for conditions which promote the interconversion between the contracted $\mathrm{V}_{24}$ octahedron and the expanded $\mathrm{V}_{24}$ ball. Interestingly, we found that the axial water molecules of vanadium centers in $\mathrm{V}_{24}$ octahedron are removed in $\mathrm{DMF} / \mathrm{CH}_{3} \mathrm{OH}(1: 1, \mathrm{v} / \mathrm{v})$ solution at $80^{\circ} \mathrm{C}$, the DMF working as a dehydrating agent; ${ }^{63}$ while those vanadium centers in $\mathrm{V}_{24}$ ballshaped capsule can capture the water molecules in $\mathrm{DMF} / \mathrm{CH}_{3} \mathrm{CN} /$ $\mathrm{H}_{2} \mathrm{O} / \mathrm{NEt}_{3}$ (20:80:10:1, v/v/v/v) solution at $80^{\circ} \mathrm{C}$ (Fig. 4). The dissociation and association of axial water molecules in vanadium centers lead to their coordination geometries changing from square pyramidal and octahedral forms (Fig. 2c and Fig. 3c), respectively. When the vanadium centers adopt octahedral geometry, they and the equatorial coordinated oxygen atoms from the Pg units are almost coplanar (Supplementary Figure 6a). In contrast, when adopting square-pyramidal geometries, the vanadium ions and those oxygen atoms form a curved surface (Supplementary Figure 6b). Such transformations between the plane and curved surfaces result in the changes of inner cavities from contracted octahedra to an expanded ball in $V_{24}$ capsules. As shown in Fig. 4, $\mathrm{V}_{24}$-oct- $\alpha$ and $\mathrm{V}_{24}$-ball- $\beta$ can be easily converted into $V_{24}$-ball- $\alpha$ and $V_{24}$-oct- $\beta$, respectively, but the reverse is not observed. However, $\mathrm{V}_{24}$-oct- $\beta$ and $\mathrm{V}_{24}$-ball- $\alpha$ can interconvert by regulating the solvents, which leads to form the $\mathrm{V}_{24}$ capsule partners showing different shapes. To sum up, the interconversions between the contracted and expanded $V_{24}$ capsules have been successfully achieved by a process involving 


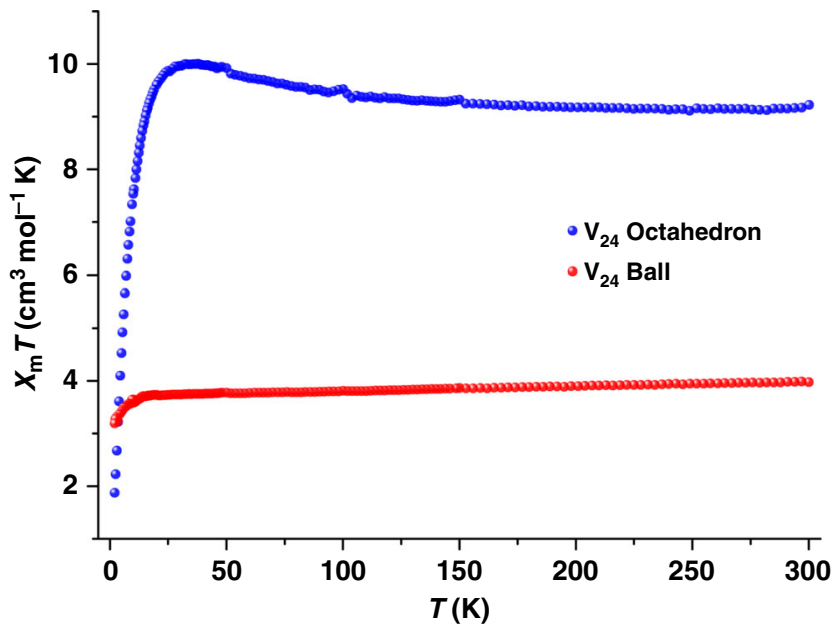

Fig. 5 Magnetic data for $V_{24}$ capsules. Plots of $\chi_{m} T$ vs. $T$ for $V_{24}$-oct- $\alpha$ and $V_{24}$-ball- $\beta$ in a $1 \mathrm{kOe}$ field

dissolution-reaction-recrystallization, which has been found to be an excellent method to explore the structural transformation of isolated coordination compounds as well as MONCs ${ }^{64-66}$. However, attempts to achieve the transformations through singlecrystal-to-single-crystal phase transition under the stimulation of temperature and pressure were hindered by poor crystal quality, because packing of these $V_{24}$ capsules is via weak supramolecular interactions, and the crystals of $\mathrm{V}_{24}$ capsules easily lose crystallinity after partial loss of the solvent.

Magnetic properties of $\mathbf{V}_{24}$ capsules. Given the structural differences between these two $V_{24}$ capsules, we compared their magnetic properties in order to yield important prototypes for exploring structure-property relationships. Here for clarity, we have provided only two phases $\left(\mathrm{V}_{24}\right.$-oct- $\alpha$ and $\mathrm{V}_{24}$-ball- $\beta$ ) as examples, because the $\chi_{\mathrm{m}} T$ vs. $\mathrm{T}$ data for $\mathrm{V}_{24}$-oct and $\mathrm{V}_{24}$-ball with two different phases show similar trends (Fig. 5 and Supplementary Figure 7). The magnetic property analyses of these two $\mathrm{V}_{24}$ capsules were performed on fresh samples from $2-300 \mathrm{~K}$ under a magnetic field of $1 \mathrm{kOe}$. For $\mathrm{V}_{24}$-oct- $\alpha$, the room temperature $\chi_{\mathrm{m}} T$ value of $9.23 \mathrm{~cm}^{3} \cdot \mathrm{K} \cdot \mathrm{mol}^{-1}$ is close to the expected value of $9 \mathrm{~cm}^{3} \cdot \mathrm{K} \cdot \mathrm{mol}^{-1}$ for 24 spin-only $\mathrm{V}^{4+}$ centers $^{50-52}$. The value increases continuously with decreasing temperature, reaching a maximum of $10.01 \mathrm{~cm}^{3} \cdot \mathrm{K} \cdot \mathrm{mol}^{-1}$ at $35 \mathrm{~K}$ and subsequently decreases sharply to $1.88 \mathrm{~cm}^{3} \cdot \mathrm{K} \cdot \mathrm{mol}^{-1}$ at $2.0 \mathrm{~K}$. The increase of the value of $\chi_{\mathrm{m}} T$ upon reduction of the temperature at higher temperatures indicates intramolecular ferromagnetic exchange between neighboring metal ions. The 35-300 K magnetic data of this capsule was fitted to the analytical experimental equation (Eq. 1) deduced for compounds with three spin centers in an equilateral triangle ${ }^{67}$, assuming the eight $\mathrm{V}_{3}$ clusters are noninteracting:

$$
\chi_{\mathrm{m}}=\frac{N \beta^{2} g^{2}}{4 k T} \frac{1+5 \exp (3 J / 2 k T)}{1+\exp (3 J / 2 k T)}
$$

In Eq. $1, N$ is Avogadro's number, $\beta$ is Bohr's magneton and $k$ is Boltzmann's constant. The best exchange interaction parameters obtained from fitting the $\chi_{\mathrm{m}}$ data are $J / k=12.38 \mathrm{~K}$ and $g$ $=1.93$ (Supplementary Figure 8). The positive $J$ value further suggests an intramolecular ferromagnetic interaction in $\mathrm{V}_{24}$-oct- $\alpha$ at higher temperatures.
For the $\mathrm{V}_{24}$-ball- $\beta$, the room temperature value of $\chi_{\mathrm{m}} T$ of 3.97 $\mathrm{cm}^{3} \cdot \mathrm{K} \cdot \mathrm{mol}^{-1}$ is much lower than the expected value $\left(9 \mathrm{~cm}^{3} \cdot \mathrm{K} \cdot \mathrm{mol}\right.$ ${ }^{-1}$ ) for 24 spin-only $\mathrm{V}^{4+}$ centers. This decreases gradually to 3.72 $\mathrm{cm}^{3} \cdot \mathrm{K} \cdot \mathrm{mol}^{-1}$ at $\sim 20 \mathrm{~K}$ and then decreases rapidly reaching a value of $3.19 \mathrm{~cm}^{3} \cdot \mathrm{K} \cdot \mathrm{mol}^{-1}$ at $2 \mathrm{~K}$. Analysis of the $\mathrm{V}_{24}$-oct- $\alpha$ using the same equation (Eq. 1) yields $J / k=-653.8 \mathrm{~K}$ and $g=2.04$ (Supplementary Figure 9). Both the curve and negative $J$ indicate dominant antiferromagnetic exchange interactions within this capsule since $\chi_{\mathrm{m}} T$ at $300 \mathrm{~K}$ is much smaller than the expected values from 24 isolated $\mathrm{V}^{4+}$ spin carriers ${ }^{68}$. Notwithstanding all $\mathrm{V}$ centers being at +4 oxidation states in both $\mathrm{V}_{24}$ capsules, the variations between the five-coordinated square-pyramidal geometries in the $\mathrm{V}_{24}$-ball- $\beta$ and the six-coordinated octahedral geometries in the $\mathrm{V}_{24}$-oct- $\alpha$ are indicative of a sensitive magnetic behavior of $\mathrm{V}^{4+}$ centers in different ligand field environments. Neither an obvious hysteresis loop or peaks for the out-of-phase component are observed for both capsules (Supplementary Figures 10-13), and this reveals no single molecule magnetic behavior above $2 \mathrm{~K}$ for both capsules.

\section{Discussion}

We have developed a strategy for the efficient construction of MONC quasi-isomers by controlling the coordination environments of the metal centers. In the present case, the adoption of octahedral and square-pyramidal geometries of vanadium centers results in a contracted $\mathrm{V}_{24}$ octahedron and an expanded $\mathrm{V}_{24}$ ball, respectively. $V_{24}$-oct- $\beta$ is the key motif in the interconversion between the contracted and expanded $V_{24}$ capsules, which can be obtained by introducing DMF to the reaction of $V_{24}$-oct- $\alpha$ and can also be prepared from $\mathrm{V}_{24}$-ball. The interconversions between $\mathrm{V}_{24}$-oct- $\beta$ and $\mathrm{V}_{24}$-ball- $\alpha$ achieved by regulating solvents, leads to formation of the $V_{24}$ capsule partners with different shapes. This work thus represents an example of MONCs whose structural differences arise from the coordination diversity of metal centers.

\section{Methods}

Materials and equipment. All reagents and solvents used in synthetic studies were obtained from commercial sources and employed without further purification. IR spectra were recorded in the range $4000-400 \mathrm{~cm}^{-1}$ with a Magna 750 IR spectrometer using $\mathrm{KBr}$ pellets. Electron paramagnetic resonance (EPR) spectra were recorded on a Bruker ER-420 spectrometer with a $100 \mathrm{kHz}$ magnetic field in the $\mathrm{X}$ band at room temperature. Magnetic susceptibilities were determined on a Quantum Design PPMS-9T and MPMS-XL systems in the range of 2-300 K. All experimental magnetic data were corrected for the diamagnetism of the sample holders and of the constituent atoms according to Pascal's constants. IR, EPR spectra and magnetic data were measured on the $V_{24}$-oct- $\alpha$ and $V_{24}$-ball- $\beta$ samples

Synthesis of $\mathbf{P g C}_{\mathbf{3}}$ ligand. A solution of pyrogallol $(20 \mathrm{~g}, 160 \mathrm{mmol})$ in ethanol $(100 \mathrm{~mL})$ and concentrated hydrochloric acid $(10 \mathrm{ml})$ was mixed dropwise with butyraldehyde $(11.4 \mathrm{~g}, 160 \mathrm{mmol})$ under $\mathrm{N}_{2}$ gas. This mixture was heated to reflux for $24 \mathrm{~h}$, cooled, filtered, washed with water, a little cold ethanol and dried under vacuum. $\mathrm{PgC}_{3}$ was collected as a colorless powder. (13.6 g, 47\%). ${ }^{1} \mathrm{H}$ NMR (400 $\mathrm{MHz}$, acetone- $\left.d_{6}\right): \delta=0.95\left(12 \mathrm{H}, \mathrm{t}, \mathrm{CH}_{3}\right), 1.31\left(8 \mathrm{H}, \mathrm{m}, \mathrm{CH}_{2}\right), 2.26\left(8 \mathrm{H}, \mathrm{q}, \mathrm{CH}_{2}\right)$, $4.35(4 \mathrm{H}, \mathrm{t}, \mathrm{CH}), 7.14(4 \mathrm{H}, \mathrm{s}, \mathrm{ArH}), 7.18(4 \mathrm{H}, \mathrm{s}, \mathrm{OH}), 8.09(8 \mathrm{H}, \mathrm{brs}, \mathrm{OH}) \mathrm{ppm}$.

Synthesis of $\mathbf{V}_{\mathbf{2 4}}$ octahedron. Method 1: $\mathrm{VOSO}_{4} \cdot 5 \mathrm{H}_{2} \mathrm{O}(0.4 \mathrm{mmol})$ and $\mathrm{PgC}_{3}(0.1$ mmol) were added to $\mathrm{CH}_{3} \mathrm{CN}(5 \mathrm{~mL}), \mathrm{H}_{2} \mathrm{O}(0.5 \mathrm{ml})$ and $\mathrm{NEt}_{3}(50 \mu \mathrm{L})$. The mixture was sealed in an $8 \mathrm{~mL}$ glass vial, which was heated at $80^{\circ} \mathrm{C}$ for three days, affording the green rhombic crystals of $\mathrm{V}_{24}$-oct- $\alpha$ with a low yield ( $8 \%$ based on the $\mathrm{PgC}_{3}$ ligand). Enhancement of the synthetic yield can be achieved by the slow concentration of the filtrate at room temperature for one week, and in this way, the total yield of $\mathrm{V}_{24}$-oct- $\alpha$ was subsequently raised to $68 \%$. Method 2 : $\mathrm{VOSO}_{4} \cdot 5 \mathrm{H}_{2} \mathrm{O}$ $(0.4 \mathrm{mmol})$ and $\mathrm{PgC}_{3}(0.1 \mathrm{mmol})$ were added to DMF $(1 \mathrm{~mL}), \mathrm{CH}_{3} \mathrm{CN}(4 \mathrm{~mL}), \mathrm{H}_{2} \mathrm{O}$ $(0.5 \mathrm{ml})$ and $\mathrm{NEt}_{3}(50 \mu \mathrm{L})$. The mixture was sealed in an $8 \mathrm{~mL}$ glass vial, which was heated at $80^{\circ} \mathrm{C}$ for $24 \mathrm{~h}$. After slow concentration of the filtrate at room temperature for one week, green block crystals of $\mathrm{V}_{24}$-oct- $\beta$ were collected in $\sim 72 \%$ yield according to the $\mathrm{PgC}_{3}$ ligand.

Synthesis of $\mathbf{V}_{\mathbf{2 4}}$ ball. Method 1: $\operatorname{VOSO}_{4} \cdot 5 \mathrm{H}_{2} \mathrm{O}(0.4 \mathrm{mmol})$ and $\mathrm{PgC}_{3}(0.1 \mathrm{mmol})$ were added to DMF $(2 \mathrm{~mL})$ and $\mathrm{CH}_{3} \mathrm{OH}(2 \mathrm{~mL})$. The mixture was sealed in an 8 $\mathrm{mL}$ glass vial, which was heated at $80^{\circ} \mathrm{C}$ for $24 \mathrm{~h}$. After slow concentration of the 
filtrate at room temperature for five days, cubic crystals of $\mathrm{V}_{24}$-ball- $\alpha$ were collected in $~ 76 \%$ yield based on the $\mathrm{PgC}_{3}$ ligand. Method 2: $\mathrm{VOSO}_{4} \cdot 5 \mathrm{H}_{2} \mathrm{O}(0.4 \mathrm{mmol})$ and $\mathrm{PgC}_{3}(0.1 \mathrm{mmol})$ were added to $\mathrm{NMF}(2 \mathrm{~mL})$ and $\mathrm{CH}_{3} \mathrm{OH}(2 \mathrm{~mL})$. The mixture was sealed in an $8 \mathrm{~mL}$ glass vial, which was heated at $80^{\circ} \mathrm{C}$ for $24 \mathrm{~h}$. After slow concentration of the filtrate at room temperature for five days, green tetragonal prism crystals of $\mathrm{V}_{24}$-ball- $\beta$ were collected in $\sim 88 \%$ yield based on the $\mathrm{PgC}_{3}$ ligand.

Conversion from $\mathbf{V}_{\mathbf{2 4}}$ octahedron to $\mathbf{V}_{\mathbf{2 4}}$ ball. In an $8 \mathrm{~mL}$ glass vial, synthesized crystals of $\mathrm{V}_{24^{-}} \mathrm{oct}-\alpha(10 \mathrm{mg})$ or $\mathrm{V}_{24^{-}}$oct- $\beta(10 \mathrm{mg})$ were dissolved in DMF $(1 \mathrm{~mL})$ and $\mathrm{CH}_{3} \mathrm{OH}(1 \mathrm{~mL})$, and the mixture was heated at $80^{\circ} \mathrm{C}$ for $48 \mathrm{~h}$. The solution was allowed to stand at room temperature for ten days to obtain $\sim 8.5 \mathrm{mg}$ green cubic crystals of $\mathrm{V}_{24}$-ball- $\alpha$, $81 \%$ yield.

Conversion from $\mathbf{V}_{\mathbf{2 4}}$ ball to $\mathbf{V}_{\mathbf{2 4}}$ octahedron. In an $8 \mathrm{~mL}$ glass vial, synthesized crystals of $\mathrm{V}_{24}$-ball- $\alpha(15 \mathrm{mg})$ or $\mathrm{V}_{24}$-ball- $\beta(15 \mathrm{mg})$ were dissolved in DMF $(0.5$ $\mathrm{mL}), \mathrm{CH}_{3} \mathrm{CN}(2 \mathrm{~mL}), \mathrm{H}_{2} \mathrm{O}(0.25 \mathrm{ml})$ and $\mathrm{NEt}_{3}(25 \mu \mathrm{L})$, and the mixture was heated at $80^{\circ} \mathrm{C}$ for $48 \mathrm{~h}$. The solution was allowed to stand at room temperature for one week to obtain $\sim 12 \mathrm{mg}$ green block crystals of $\mathrm{V}_{24}$-oct- $\beta, 83 \%$ yield.

Single crystal X-ray diffractions. All X-ray single crystal data for $\mathrm{V}_{24}$ capsules were measured on diffractometers equipped with copper micro-focus X-ray sources $(\lambda=1.5406 \AA)$ at $100.0(2) \mathrm{K}$. Diffraction data from $V_{24^{-}}$oct- $\alpha, V_{24^{-}}$ball- $\beta$ and $V_{24^{-}}$ ball- $\alpha$ were measured on a SuperNova diffractometer, and that from $V_{24}$-oct- $\beta$ was collected on Bruker APEX-II CCD. The crystal structures were resolved by direct methods and all calculations were performed on the SHELXTL-2016 program package ${ }^{69}$. All non-hydrogen atoms were refined anisotropically with the exception of several highly disordered propyl carbon atoms and water molecules. Hydrogen atoms of the organic ligands were added in the riding model and refined with isotropic thermal parameters. Because of the diffuse electron density and the highly disordered/amorphous solvents, molecules of crystallization could not be fully located and were therefore not included for all structures (details are also provided in Supplementary Note 1). The crystal structures were treated by the "SQUEEZE" routine $^{70}$, a part of the PLATON package of crystallographic software, dramatically improving the agreement indices. We attempted to finish the refinement, but the $R_{1}$ and $w R_{2}$ factors were still high and some A-alerts were found by the (IUCr) checkCIF routine, all of which could be ascribed to the weak crystal diffraction, which is typical in giant supramolecular assemblies. Details on crystal data collection and refinement for these capsules are summarized in Supplementary Table 1 .

\section{Data availability}

The X-ray crystallographic coordinates for structures reported in this article have been deposited at the Cambridge Crystallographic Data Centre (CCDC), under deposition numbers CCDC $1535802\left(\mathrm{~V}_{24}\right.$-oct- $\left.\alpha\right)$; CCDC 1811159 ( $\mathrm{V}_{24}$-oct- $\beta$ ); CCDC $1535804\left(\mathrm{~V}_{24}\right.$-ball- $\left.\alpha\right)$; and CCDC 1535803 ( $\mathrm{V}_{24}$-ball- $\left.\beta\right)$. These data can be obtained free of charge from The Cambridge Crystallographic Data Centre (CCDC) via www.ccdc.cam.ac.uk/data_request/cif.

Received: 18 May 2018 Accepted: 22 October 2018

Published online: 22 November 2018

\section{References}

1. Caulder, D. L. \& Raymond, K. N. Supermolecules by design. Acc. Chem. Res. 32, 975-982 (1999).

2. Cook, T. R. \& Stang, P. J. Recent developments in the preparation and chemistry of metallacycles and metallacages via coordination. Chem. Rev. 115, 7001-7045 (2015).

3. Byrne, K. et al. Ultra-large supramolecular coordination cages composed of endohedral archimedean and platonic bodies. Nat. Commun. 8, 15268 (2017).

4. Brown, C. J., Toste, F. D., Bergman, R. G. \& Raymond, K. N. Supramolecular catalysis in metal-ligand cluster hosts. Chem. Rev. 115, 3012-3035 (2015).

5. Pluth, M. D. \& Raymond, K. N. Reversible guest exchange mechanisms in supramolecular host-guest assemblies. Chem. Soc. Rev. 36, 161-171 (2007).

6. Zhang, T., Zhou, L.-P., Guo, X.-Q., Cai, L.-X. \& Sun, Q.-F. Adaptive selfassembly and induced-fit transformations of anion-binding metal-organic macrocycles. Nat. Commun. 8, 15898 (2017).

7. Kaphan, D. M., Levin, M. D., Bergman, R. G., Raymond, K. N. \& Toste, F. D. A supramolecular microenvironment strategy for transition metal catalysis. Science 350, 1235-1238 (2015).

8. Yeung, C.-T. et al. Chiral transcription in self-assembled tetrahedral eu4l6 chiral cages displaying sizable circularly polarized luminescence. Nat. Commun. 8, 1128 (2017).
9. Wu, K. et al. Homochiral d-4-symmetric metal-organic cages from stereogenic ru(ii) metalloligands for effective enantioseparation of atropisomeric molecules. Nat. Commun. 7, 10487 (2016)

10. Dai, F. R., Sambasivam, U., Hammerstrom, A. J. \& Wang, Z. Synthetic supercontainers exhibit distinct solution versus solid state guest-binding behavior. J. Am. Chem. Soc. 136, 7480-7491 (2014).

11. Sun, Q. F. et al. Self-assembled $\mathrm{m} 24148$ polyhedra and their sharp structural switch upon subtle ligand variation. Science 328, 1144-1147 (2010).

12. Pasquale, S., Sattin, S., Escudero-Adán, E. C., Martínez-Belmonte, M. \& de Mendoza, J. Giant regular polyhedra from calixarene carboxylates and uranyl. Nat. Commun. 3, 785 (2012).

13. McConnell, A. J., Wood, C. S., Neelakandan, P. P. \& Nitschke, J. R. Stimuliresponsive metal-ligand assemblies. Chem. Rev. 115, 7729-7793 (2015).

14. Wang, W., Wang, Y.-X. \& Yang, H.-B. Supramolecular transformations within discrete coordination-driven supramolecular architectures. Chem. Soc. Rev. 45, 2656-2693 (2016).

15. Murase, T., Sato, S. \& Fujita, M. Switching the interior hydrophobicity of a self-assembled spherical complex through the photoisomerization of confined azobenzene chromophores. Angew. Chem. Int. Ed. 46, 5133-5136 (2007).

16. Park, J., Sun, L.-B., Chen, Y.-P., Perry, Z. \& Zhou, H.-C. Azobenzenefunctionalized metal-organic polyhedra for the optically responsive capture and release of guest molecules. Angew. Chem. Int. Ed. 53, 5842-5846 (2014).

17. Frank, M. et al. Assembly and stepwise oxidation of interpenetrated coordination cages based on phenothiazine. Angew. Chem. Int. Ed. 52, 10102-10106 (2013).

18. Hiraoka, S., Sakata, Y. \& Shionoya, M. Ti(iv)-centered dynamic interconversion between $\mathrm{pd}(\mathrm{ii})$, ti(iv)-containing ring and cage molecules. J. Am. Chem. Soc. 130, 10058-10059 (2008).

19. Riddell, I. A. et al. Anion-induced reconstitution of a self-assembling system to express a chloride-binding colol15 pentagonal prism. Nat. Chem. 4, 751-756 (2012).

20. Stephenson, A., Argent, S. P., Riis-Johannessen, T., Tidmarsh, I. S. \& Ward, M. D. Structures and dynamic behavior of large polyhedral coordination cages: an unusual cage-to-cage interconversion. J. Am. Chem. Soc. 133, 858-870 (2011).

21. Rizzuto, F. J. \& Nitschke, J. R. Stereochemical plasticity modulates cooperative binding in a (co1216)-1-ii cuboctahedron. Nat. Chem. 9, 903-908 (2017).

22. Zhang, D. et al. Anion binding in water drives structural adaptation in an azaphosphatrane-functionalized feii4l4 tetrahedron. J. Am. Chem. Soc. 139, 6574-6577 (2017).

23. Huang, R.-W. et al. Hypersensitive dual-function luminescence switching of a silver-chalcogenolate cluster-based metal-organic framework. Nat. Chem. $\mathbf{9}$, 689-697 (2017)

24. Chen, Y. et al. Isomerism in au-28(sr)(20) nanocluster and stable structures. J. Am. Chem. Soc. 138, 1482-1485 (2016)

25. Mirtschin, S., Slabon-Turski, A., Scopelliti, R., Velders, A. H. \& Severin, K. A coordination cage with an adaptable cavity size. J. Am. Chem. Soc. 132, 14004-14005 (2010).

26. Noh, T. H., Heo, E., Park, K. H. \& Jung, O.-S. Motion of an isolated water molecule within a flexible coordination cage: Structural properties and catalytic effects of ionic palladium(ii) complexes. J. Am. Chem. Soc. 133, 1236-1239 (2011).

27. Kumari, H., Deakyne, C. A. \& Atwood, J. L. Solution structures of nanoassemblies based on pyrogallol 4 arenes. Acc. Chem. Res. 47, 3080-3088 (2014).

28. Dalgarno, S. J., Power, N. P. \& Atwood, J. L. Metallo-supramolecular capsules. Coord. Chem. Rev. 252, 825-841 (2008).

29. Jin, P., Dalgarno, S. J. \& Atwood, J. L. Mixed metal-organic nanocapsules. Coord. Chem. Rev. 254, 1760-1768 (2010).

30. Cave, G. W. V., Antesberger, J., Barbour, L. J., McKinlay, R. M. \& Atwood, J. L. Inner core structure responds to communication between nanocapsule walls. Angew. Chem. Int. Ed. 43, 5263-5266 (2004).

31. Dalgarno, S. J., Bassil, D. B., Tucker, S. A. \& Atwood, J. L. Cocrystallization and encapsulation of a fluorophore with hexameric pyrogallol[4]arene nanocapsules: Structural and fluorescence studies. Angew. Chem. Int. Ed. 45, 7019-7022 (2006)

32. Kumari, H., Dennis, C. L., Mossine, A. V., Deakyne, C. A. \& Atwood, J. L. Magnetic differentiation of pyrogallol 4 arene tubular and capsular frameworks. J. Am. Chem. Soc. 135, 7110-7113 (2013).

33. Kumari, H. et al. Solution-phase and magnetic approach towards understanding iron gall ink-like nanoassemblies. Angew. Chem. Int. Ed. 51, 9263-9266 (2012)

34. Patil, R. S., Banerjee, D., Zhang, C., Thallapally, P. K. \& Atwood, J. L. Selective co2 adsorption in a supramolecular organic framework. Angew. Chem. Int. Ed. 55, 4523-4526 (2016)

35. McKinlay, R. M., Cave, G. W. \& Atwood, J. L. Supramolecular blueprint approach to metal-coordinated capsules. Proc. Natl Acad. Sci. USA 102, 5944-5948 (2005) 
36. Kumari, H. et al. Controlling the self-assembly of metal-seamed organic nanocapsules. Angew. Chem. Int. Ed. 51, 1452-1454 (2012).

37. Rathnayake, A. S. et al. Investigating reaction conditions to control the selfassembly of cobalt-seamed nanocapsules. Cryst. Growth Des. 16, 3562-3564 (2016).

38. Zhang, C., Patil, R. S., Liu, C., Barnes, C. L. \& Atwood, J. L. Controlled $2 \mathrm{~d}$ assembly of nickel-seamed hexameric pyrogallol[4]arene nanocapsules. J. Am. Chem. Soc. 139, 2920-2923 (2017).

39. Zhang, C., Patil, R. S., Li, T., Barnes, C. L. \& Atwood, J. L. Self-assembly of magnesium-seamed hexameric pyrogallol[4]arene nanocapsules. Chem. Commun. 53, 4312-4314 (2017).

40. Rathnayake, A. S., Barnes, C. L. \& Atwood, J. L. Zinc(ii)-directed self-assembly of metal-organic nanocapsules. Cryst. Growth Des. 17, 4501-4503 (2017).

41. Power, N. P., Dalgarno, S. J. \& Atwood, J. L. Guest and ligand behavior in zinc-seamed pyrogallol 4 arene molecular capsules. Angew. Chem. Int. Ed. 46, 8601-8604 (2007).

42. Atwood, J. L. et al. Magnetism in metal-organic capsules. Chem. Commun. 46, 3484-3486 (2010).

43. Maerz, A. K., Thomas, H. M., Power, N. P., Deakyne, C. A. \& Atwood, J. L. Dimeric nanocapsule induces conformational change. Chem. Commun. 46, 1235-1237 (2010).

44. McKinlay, R. M., Thallapally, P. K., Cave, G. W. V. \& Atwood, J. L. Hydrogenbonded supramolecular assemblies as robust templates in the synthesis of large metal-coordinated capsules. Angew. Chem. Int. Ed. 44, 5733-5736 (2005).

45. Jin, P., Dalgarno, S. J., Barnes, C., Teat, S. J. \& Atwood, J. L. Ion transport to the interior of metal-organic pyrogallol[4]arene nanocapsules. J. Am. Chem. Soc. 130, 17262-17263 (2008).

46. Kumari, $\mathrm{H}$. et al. Strong cation center dot center dot center dot pi interactions promote the capture of metal ions within metal-seamed nanocapsule. J. Am. Chem. Soc. 136, 17002-17005 (2014).

47. Jin, P., Dalgarno, S. J., Warren, J. E., Teat, S. J. \& Atwood, J. L. Enhanced control over metal composition in mixed ga/zn and ga/cu coordinated pyrogallol[4] arene nanocapsules. Chem. Commun. 45, 3348-3350 (2009).

48. Fowler, D. A. et al. Coordination polymer chains of dimeric pyrogallol[4]arene capsules. J. Am. Chem. Soc. 133, 11069-11071 (2011).

49. Mossine, A. V. et al. Zinc-seamed pyrogallol 4 arene dimers as structural components in a two-dimensional mof. Chem. Sci. 5, 2297-2303 (2014).

50. Aronica, C. et al. A mixed-valence polyoxovanadate(iii,iv) cluster with a calixarene cap exhibiting ferromagnetic v(iii)-v(iv) interactions. J. Am. Chem. Soc. 130, 2365-2371 (2008).

51. Gautier, R. et al. Spin frustration from cis-edge or -corner sharing metalcentered octahedra. J. Am. Chem. Soc. 135, 19268-19274 (2013).

52. Rasmussen, M. et al. Small, beautiful and magnetically exotic: $\{\mathrm{v} 4 \mathrm{w} 2\}$ - and \{v4w4\}-type polyoxometalates. Dalton. Trans. 45, 10519-10522 (2016).

53. Chen, L. et al. A basket tetradecavanadate cluster with blue luminescence. J. Am. Chem. Soc. 127, 8588-8589 (2005).

54. Santoni, M.-P. et al. The use of a vanadium species as a catalyst in photoinduced water oxidation. J. Am. Chem. Soc. 136, 8189-8192 (2014).

55. Zhang, Z., Wojtas, L. \& Zaworotko, M. J. Organic-inorganic hybrid polyhedra that can serve as supermolecular building blocks. Chem. Sci. 5, 927-931 (2014).

56. Abrahams, B. F., Fitzgerald, N. J. \& Robson, R. Cages with tetrahedron-like topology formed from the combination of cyclotricatechylene ligands with metal cations. Angew. Chem. Int. Ed. 49, 2896-2899 (2010).

57. Mahimaidoss, M. B. et al. Homologous size-extension of hybrid vanadate capsules-solid state structures, solution stability and surface deposition. Chem. Commun. 50, 2265-2267 (2014).

58. Zhang, Y.-T. et al. Anderson-like alkoxo-polyoxovanadate clusters serving as unprecedented second building units to construct metal-organic polyhedra. Chem. Commun. 52, 9632-9635 (2016).

59. Gerkensmeier, T. et al. Self-assembly of 2,8,14,20-tetraisobutyl-5,11,17,23tetrahydroxyresorc 4 arene. Eur. J. Org. Chem. 1999, 2257-2262 (1999).

60. Hanson, G. R., Sun, Y. \& Orvig, C. Characterization of the potent insulin mimetic agent bis(maltolato)oxovanadium(iv) (bmov) in solution by epr spectroscopy. Inorg. Chem. 35, 6507-6512 (1996).

61. Liboiron, B. D. et al. New insights into the interactions of serum proteins with bis(maltolato)oxovanadium(iv): Transport and biotransformation of insulinenhancing vanadium pharmaceuticals. J. Am. Chem. Soc. 127, 5104-5115 (2005).
62. Sanna, D., Buglyo, P., Biro, L., Micera, G. \& Garribba, E. Coordinating properties of pyrone and pyridinone derivatives, tropolone and catechol toward the vo2+ ion: an experimental and computational approach. Eur. J. Inorg. Chem. 2012, 1079-1092 (2012).

63. Muzart, J. N. n-dimethylformamide: much more than a solvent. Tetrahedron 65, 8313-8323 (2009).

64. Li, S. et al. Atom-precise modification of silver(i) thiolate cluster by shell ligand substitution: a new approach to generation of cluster functionality and chirality. J. Am. Chem. Soc. 140, 594-597 (2018).

65. Ronson, T. K., Pilgrim, B. S. \& Nitschke, J. R. Pathway-dependent postassembly modification of an anthracene-edged (m416)-l-ii tetrahedron. J. Am. Chem. Soc. 138, 10417-10420 (2016).

66. He, Y. P. et al. Water-soluble and ultrastable ti4l6 tetrahedron with coordination assembly function. J. Am. Chem. Soc. 139, 16845-16851 (2017).

67. Kahn, O. Molecular Magnetism. (VCH, Weinheim, Germany, 1993).

68. Rasmussen, M., Naether, C., van Leusen, J., Koegerler, P. \& Bensch, W. A keggin-type structure expanded by an eight-membered ring of alternating edge-sharing vo5 and vo6 polyhedra: Solvothermal synthesis, crystal structure, and magnetic properties. Eur. J. Inorg. Chem. 2015, 3285-3289 (2015).

69. Sheldrick, G. M. Crystal structure refinement with SHELXL. Acta Crystallogr. C. 71, 3-8 (2015).

70. Spek, A. L. Single-crystal structure validation with the program PLATON. J. Appl. Crystallogr. 36, 7-13 (2003).

\section{Acknowledgements}

This work was financially supported by the Strategic Priority Research Program of the Chinese Academy of Sciences (XDB20000000), Key Research Program of Frontier Sciences, CAS (QYZDB-SSW-SLH019), National Nature Science Foundation of China (21771177, 51603206 and 21390392), and the Nature Science Foundation of Fujian Province (2016J05056). We would like to thank Dr. Scott Dalgarno and Prof. Qingfu Sun for helpful discussions.

\section{Author contributions}

D.Q.Y. and M.C.H. proposed the ideas and supervised the project. K.Z.S. performed all the experiments. D.Q.Y., K.Z.S., and M.Y.W. analyzed the data and wrote the manuscript. All authors discussed the results and commented on the manuscript.

\section{Additional information}

Supplementary Information accompanies this paper at https://doi.org/10.1038/s41467018-07427-z.

Competing interests: The authors declare no competing interests.

Reprints and permission information is available online at http://npg.nature.com/ reprintsandpermissions/

Publisher's note: Springer Nature remains neutral with regard to jurisdictional claims in published maps and institutional affiliations.

Open Access This article is licensed under a Creative Commons Attribution 4.0 International License, which permits use, sharing, adaptation, distribution and reproduction in any medium or format, as long as you give appropriate credit to the original author(s) and the source, provide a link to the Creative Commons license, and indicate if changes were made. The images or other third party material in this article are included in the article's Creative Commons license, unles indicated otherwise in a credit line to the material. If material is not included in the article's Creative Commons license and your intended use is not permitted by statutory regulation or exceeds the permitted use, you will need to obtain permission directly from the copyright holder. To view a copy of this license, visit http://creativecommons.org/ licenses/by/4.0/.

(C) The Author(s) 2018 